\title{
2
}

\section{THINKING OUTSIDE THE BOX (PART 1): REAL LIVING STANDARDS}

\subsection{OVERVIEW}

When comparing regional living standards, we're typically most interested in the welfare of residents of an area (rather than its workforce). This chapter discusses the preferred welfare measure of many in the Office for National Statistics (ONS) (Dunnell, 2009) - gross disposable household income (GDHI) - before touching on a measure of deprivation, namely the Index of Multiple Deprivation (IMD). This has critical salience for those 'left-behind' (Goodwin \& Heath, 2016) in the 'places that don't matter' who voted most strongly to leave the European Union (EU) (Rodríguez-Pose, 2018). The chapter is structured as follows:

- Introduction - This section gives a brief discussion of GDHI per capita, its component parts and the regionalisation process adopted by the ONS.

- Price levels - Here we introduce a more detailed discussion of the primary weakness of the GDHI measure: its failure to account for different living costs across 
regions. We draw on the latest data to develop and appropriate correction for this and demonstrate its impact.

- Operating surplus - This addresses a further relatively minor technical issue in the regionalisation process used to account for imputed rent.

- Inequality - GDHI takes no account of inequality and this section discusses the possible scale of the issue.

- IMD - Here we briefly discuss the IMD, noting its advantages and disadvantages, and show that it requires similar corrections to GDHI in order to take account differences in the cost of living across Britain.

\subsection{INTRODUCTION}

GDHI per capita is a measure of average regional living standards. It includes household income from all sources and, unlike GVA, is calculated on the basis of residency. Thus, if a pensioner living in Devon receives investment income that is ultimately generated by profits from a company in London then it is counted as disposable income in the South West. As such, it is a superior measure of average living standards, but should not be used to measure productivity, regional output or to describe the economic geography of an area.

GDHI is defined by the ONS as being 'the amount of money that individuals in the household sector have available for spending or saving [...] after expenditure associated with income, for example taxes and social contributions' (West et al., 2016, p. 34). The regional GDHI figures published by the ONS are compiled on a 'top-down' basis. In practical terms, this means that the ONS begins with national aggregates for each component part of GDHI and then uses a variety of indicators to apportion them in turn to each region. 
GDHI does not map neatly to the 'cash income' of individuals as it includes implicit income, such as the implicit rent earned by owner-occupiers. In fact, this is a strength rather than a weakness - the fact that no money physically changes hands should not blind us to the fact that owner-occupiers receive 'income' in the form of not having to pay rent. In effect, they pay rent to themselves. A further major strength of GDHI per capita is that, unlike measures of deprivation, it includes the entire population in its scope. Whilst attention is rightly focussed on the very poor, a true measure of overall regional welfare should include those 'just about managing' (Parkinson, 2016), the middle classes and the well-off. Indeed, Sayer (2017) sees the focus on income and the 'left behind' as overdone (although the evidence of Becker, Fetzer, \& Novy, 2017) seems to contradict this.

GDHI does have major weaknesses. Firstly, like gross domestic product per capita, it tells us nothing about inequality. Most importantly of all, it measures income in purely nominal terms. Whilst it may appear sensible to measure income in terms of pounds and pence, the reality is that the cost of living varies enormously across regions. In many ways this is intuitively obvious: anyone who has spent time in both London and other parts of the country will be well aware of how much further your money goes in the latter. A classic example of this is the cost of an average pint of beer - in London this is $£ 4.20$, whereas in Herefordshire it's just $£ 3.31{ }^{1}$

\subsection{PRICE LEVELS}

An accurate measure of regional living standards must adjust for these differences in regional price levels. In this chapter, we build on the methodology introduced in Hearne (Forthcoming-b) and use the very latest data to show that accounting 
for different regional price levels more than halves the disparity between London and Yorkshire in 2016. This has very obvious ramifications for regional policy and particularly for post-Brexit funding flows. It also refines our existing perceptions of the UK's 'regional problem' (Hardill, Benneworth, Baker, \& Budd, 2006) and spatial imbalances and suggests both challenges to, and further scope to develop, the Government's 'Northern Powerhouse', 'Midlands Engine' and 'Industrial Strategy' agendas.

Interestingly, whilst the UK practice of using nominal data is standard within Europe, it is by no means universal internationally. The Bureau of Economic Analysis in the United States, for example, publishes estimates of regional price parities and finds that prices in the state of New York are $34 \%$ higher than those of Mississippi. The effects are dramatic: instead of New Yorkers being $69 \%$ better off than Mississippians, in real terms the gap is a less extreme $26 \%$ (Aten, Figueroa, Mbu, \& Vengelen, 2017). Our work seeks to develop figures for the UK in line with this international best practice.

The pattern of areas with high nominal incomes also experiencing higher than average price levels is well established, particularly within the academic literature on international economics (see Asea \& Corden, 1994, for an overview). There is growing evidence that the same is true on a regional level, with examples as diverse as Italy (Nenna, 2001) and China (Jiang \& Li, 2006), amongst others. It's thus likely, prima facie, that the same is true within the UK. There is now a mature, high quality academic literature investigating regional differences and inequalities both within the UK and internationally (see McCann, 2016, for an in-depth treatment of the UK case, work from Beugelsdijk, Klasing, \& Milionis, 2018, for an example of the Europe-wide debate and Lemoine, Poncet, \& Ünal, 2015, for a discussion of the Chinese case). 
Nevertheless, in spite of its importance, only a modest portion of this work has focussed on regional prices. This has not been lost on many observers: as Blien, Gartner, Stüber, and Wolf $(2009$, p. 17) note, '[T] hough the value of information on regional prices is obvious, there is a lack of empirical data in many countries'. Official interest in regional prices in the UK initially surfaced in the 1960s (Retail Prices Index Advisory Committee, 1971), but little was done. In fact, only with the advent of Eurostat's need for Spatial Adjustment Factors did official attention return to the matter.

In the interim, and particularly during the 1990s, academic attention was paid to the development of regional price indices. Regional prices diverged significantly over the course of the 1980s (Borooah, McGregor, McKee, \& Mulholland, 1996), and this had a noteworthy effect on the spatial distribution real wages for both manual and non-manual workers (Martin \& Tyler, 1994). Indeed, Johnston, McKinney, and Stark (1996) found that the cost of living in London went from being $5 \%$ greater than the UK average to $7.5 \%$ between the beginning and end of the 1980s. Hayes (2005) attempted to create a pure 'price index' and found that from 1979 to 1996, inflation across regions was highly correlated but that there was some regional heterogeneity.

All of these authors made use of the regional price data collected by the Croner-Reward Cost of Living Surveys, which were the only data available on regional prices during the period in question. Today, we have the luxury of using official data, which whilst only collected every six years do have considerably larger sample sizes. The Croner-Reward data in question were discontinued and all the academic articles in question refer to prices in the mid-1990s or earlier.

A second change over the past two decades is methodological. Much previous work (see e.g Borooah et al., 1996; Rienzo, 2017) drew on the methodology used by the retail 
price index (RPI), which was at the time the gold standard measure of inflation in the UK. Today, the ONS has moved away from using the RPI as new, internationally comparable, measures of inflation have been developed which incorporate the latest developments and techniques.

Deciding on the most appropriate method to compare prices across regions is unfortunately not as straightforward as it might at first appear. This is primarily due to the fact that not all prices differ by the same amount: the cost of broadband is broadly similar in London or Newcastle, but the cost of putting a roof over one's head definitely isn't. Londoners typically spend a greater proportion of their income on housing and live in smaller properties than those in the North East. This problem is compounded by the fact that consumption patterns can differ across regions. For example, the presence of a high quality mass transit network in London combined with high levels of congestion means that transport spending differs in both amount and composition (ONS, 2017d).

We use the same methodology and data sources outlined in Hearne (Forthcoming-b). Since that work, however, the ONS have released relative regional consumer price levels (RRCPLs) for 2016 allowing us to provide an up-to-date assessment of relative regional living standards. The 2016 ONS RRCPLs are used as the base for our calculations. The ONS do not include housing costs in the RRCPLs, so our work needs to appropriately incorporate housing costs in order to assess the true cost of living in each region.

Additionally, as outlined in Hearne (Forthcoming-b), our figures are compiled on the basis of the spending of residents of a region, whereas the ONS' RRCPLs are compiled on the basis of what is spent in a region rather than on the basis of what is spent by residents of a region. As a result, they do not include money spent by residents outside of the region but they do include that spent by non-residents inside the region (e.g. by tourists). Whilst this is conceptually correct for their 
purposes, it is not appropriate for assessing living standards. As a result, we adjust for both factors.

As in 2010, a detailed breakdown of regional prices is not available at the division level (ONS, 2011). Two options are available at this point in order to operationalise our calculation of relative regional prices. The first is to assume that prices for all goods except housing are identical in English regions outside London (allowing one to use the detailed breakdowns available for Scotland, Wales, London and 'Rest of England'). The second alternative is to use the aggregated figures available by region, but accept that division-level results are not available. As non-housing costs inside England (excluding the capital) appear to differ by over $5 \%$ the second approach seems the most sensible.

We therefore break up each region's total spending into five constituent parts:

(1) Expenditure categories accounted for by the RRCPLs (this represented the majority of total consumer spending in every region - typically around $65 \%$ ).

(2) Expenditure on things whose prices were assumed not to vary across regions (primarily holiday expenditure).

(3) Expenditure on privately rented housing.

(4) Expenditure on socially rented housing.

(5) Owner occupiers housing costs.

Health and (private) education spending by consumers fell into the second category - prescription charges are uniform across England and prices for items such as glasses and contact lenses are unlikely to vary much. In the absence of any further data, private education and health care is assumed to be equally costly irrespective of location. This is unlikely to have a major effect on the total price index as both items combined account for around $2.5 \%$ of total spending in the UK. 
Two main data sources are used. The living costs and food (LCF) survey is used to ascertain what proportion of total spending is accounted for by each category. ${ }^{2}$ In order to do so, two transformations are needed. The LCF survey gives an inventory of average total expenditure per household in each region. Unfortunately, not all forms of expenditure are relevant for the calculation of price levels. As a result, we exclude those things that are not relevant to a price index (specifically, mortgage interest payments, savings and cash transfers and gifts). Similarly, the housing services enjoyed by owner-occupiers are implicit rather than explicit.

This is important: estimates of incomes and price levels need to be constructed on a systematic and consistent basis. In order to do so, it is necessary to distinguish the cost of putting a roof over one's head (what we're interested in) from the cost of buying a house as an asset. In essence, we need to split the 'owner' from the 'occupier'. The conceptually correct way to do this is as follows: the occupant pays rent to the owner. As both are the same person in this case no money actually changes hands - the transaction is implicit.

From the perspective of the occupant, the implicit rent paid can be thought of as the true cost of putting a roof over one's head. As this is a service, it needs to be included in any measure of the cost of living. From the perspective of the owner, the rent received is part of the return earned from owning the asset (i.e. the property). This can be thought of as similar to the dividend from a share or coupon on a bond. ${ }^{3}$ The remainder of the return is the capital gain or loss realised upon the sale of the property.

How much should this 'implicit' rental payment actually be? The obvious solution is also the correct one: the price of renting an identical property on the private market. Whilst, in practical terms, this is likely to be almost impossible for certain types of properties in some areas (e.g. the rental market for 
four bedroom houses in most areas is rather thin), when comparing across larger regions this does not present a problem.

The proportion of total expenditure accounted for by imputed rents can be estimated by multiplying total spending on gross rents in the LCF survey by:

Proportion of owner occupiers in region $\div$

Proportion of renters in region

The proportion of owner-occupiers by region can be ascertained from the Family Resources Survey (FRS). This also allows one to break down rents into the private and social renting sectors. The FRS was also used to estimate relative rental prices for both sectors (private and social rents). Private rents are the appropriate yardstick to use for the cost of owner-occupied housing.

\subsection{OPERATING SURPLUS}

One additional, relatively minor, issue relates to the method used by the ONS for apportioning imputed rents. Gross operating surplus represents around $10 \%$ of primary resources in the UK as a whole (typically rather more in London and the South East) and 'relates to the household sector's rental income from buildings, including the imputed rental of owner-occupier dwellings' (West et al., 2016, p. 36).

As noted previously, regional GDHI is calculated on a top-down basis by allocating a proportion of each national component (operating surplus, mixed income, compensation of employees, etc.) to regions and then summing them. As the ONS points out, ' $[\mathrm{t}]$ he national operating surplus total is regionalised using estimates of median property prices by region'. This approach implicitly assumes that regional rents are perfectly correlated with median regional property prices. 
In theory this should be the case: property is an asset and if the returns on that asset are greater in one region than in another then there is a clear incentive to purchase property in the region which offers greater returns. Several factors, however, suggest that this may not be the case in practice. Firstly, rents from a property form only part of the expected returns they are the running yield, with the remainder of the expected returns accounted for by anticipated capital appreciation. This speculation appears to have played a significant part in divergent trends in property prices in recent years.

Secondly, imperfections in capital markets and frictions associated with buying and selling property may mean that any equilibrating forces act only slowly. Experimental statistics from the ONS suggest that house prices have diverged to a much greater extent than rents since 2010. In particular, between January 2011 and January 2018, rents in the North East increased by $4.3 \%$ compared to $23 \%$ in London (ONS, 2018c). In contrast, house prices increased by $5.1 \%$ in the North East and $69 \%$ in London over the same period (ONS, 2018h).

As a result, using house prices rather than rents will lead to GDHI overstating improvements in living standards in London relative to those in the North East. Whilst the effects are modest relative to the changes induced by accounting for price differences, they compress the gap between London and the North still further. After recalculating the figures using the relative rents in the FRS, we find that Londoners are only $20 \%$ better off than their counterparts in the North East and those in the South East around $16 \%$ better off than the inhabitants of Yorkshire.

Naturally, the FRS is not an infallible data source either: sample sizes are relatively small and relative regional rents vary substantially from year to year. Moreover, data from the Valuations Office Agency (2017) and Unison (2017) suggest that regional disparities in rents are significantly greater than the FRS would 
indicate. As a result we are faced with an alternative - the 'Operating Surplus' portion of GDHI contains an implicit measure of relative regional housing costs. If we follow the regionalisation procedure outlined by the ONS (West et al., 2016) in reverse (by using data on housing stock by region) then we can calculate the relative regional housing costs implied by the GDHI.

\subsection{THE RESULTS}

This completes work to find a set of appropriate expenditure weights for each region. We can then use the relative prices provided by the FRS or those 'back calculated' from the GDHI for housing costs and the RRCPLs for everything else. The Èltetö-Köves-Szulc procedure (explained in greater depth in Appendix 2) can then be used to calculate relative prices, based upon the five categories. ${ }^{4}$ Whilst in theory the slightly different aggregation procedure we use relative to the OECD (as a result of data limitations) could have an impact on the price levels we calculate, in practice the difference is likely to be tiny (and in all probability dwarfed by measurement error in the ONS surveys used).

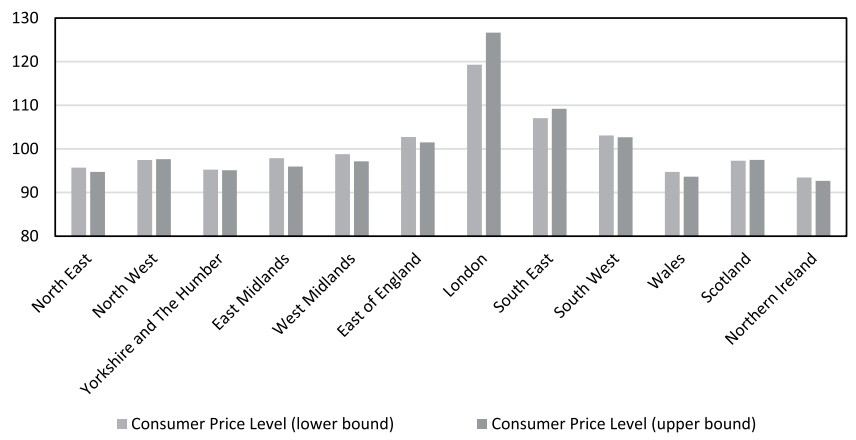

Fig. 2. Estimated Regional Consumer Price Levels.

Source: authors' calculations. 
As can be seen in Fig. 2, whilst the choice of measure for housing costs does indeed make a difference, the overall pattern of results is clear in either case. London is, by far, the most expensive region in the UK in which to live. This is followed by other southern parts of the UK with the northern regions of England and Wales proving to be the cheapest parts of the country to live. This fits rather well with common perceptions of prices in different parts of the country.

\subsection{REAL REGIONAL GDHI}

The next graph (Fig. 3) shows the impact of regional price variations on household incomes across Great Britain. 'Method 1' in the graph refers to using the FRS data on housing costs but re-allocating households operating surplus across regions on this basis of these. 'Method 2' uses the nominal regional GDHI figures as-is but the deflator uses the estimates of housing-costs derived directly from the GDHI itself. Both figures ultimately deliver extremely close results.

The principal impact is to greatly narrow the divide between North and South. The impact on London is particularly striking: the average Londoner falls from being $71 \%$ better off than their Welsh counterpart to being 'only' $27 \%$ better off. Whilst this remains a substantial difference, it is not the veritable chasm that official data make it look. Moreover, although London is an outlier, an attenuated version of the same phenomenon is visible across the UK: the gap between Yorkshire and the South East falls from $37 \%$ to $19 \%$, for example.

Moreover, this analysis alters the ranking of regions within the UK. The North East, Yorkshire \& Humberside and Wales all overtake the West Midlands due to their lower cost of living. Scotland appears as well off as the 'East of England' (comprising Hertfordshire, Essex and Bedfordshire as well as East Anglia) and at least as well off as the South West. 


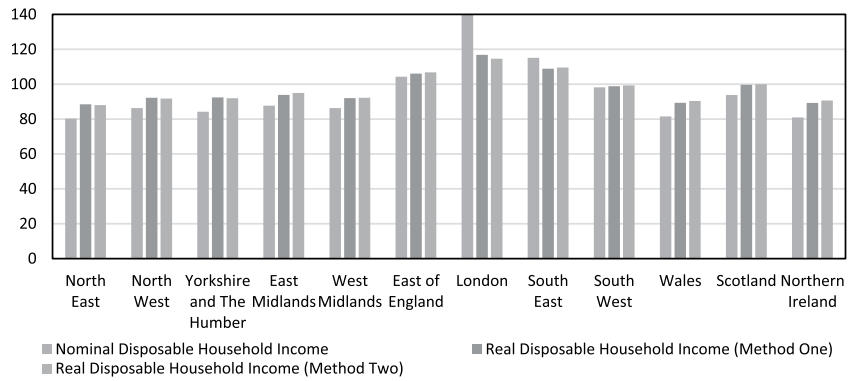

Fig. 3. Real Regional Incomes in the UK.

Sources: Nominal Gross Disposable Household Income (ONS, 2018f). Real Gross Disposable Household Income (authors' calculations - both methods).

The same fundamental point will apply to any regional data regarding incomes. Wages are proportionately affected, for example. Moreover, the phenomenon is equally visible at the level of urban subregions. If we assume that price levels differ across regions but are broadly constant within them, ${ }^{5}$ then some indicative comparisons are possible. In Fig. 4 below, we consider the case of the Combined Authorities (plus London). As can be seen, the broad pattern exhibited by the nominal data remains unchanged, although the gaps between regions are smaller. The clear exception to this rule is the West Midlands, which falls further behind its peers as the poorest Combined Authority in the UK. Again, this is interesting in light of the Brexit vote - a number of local authorities in this area had an exceptionally large vote in favour of leaving the EU. The other notable feature is that London stands out far less: this is particularly true when one considers that London itself contains a handful of standout boroughs (most notably Kensington \& Chelsea, Hammersmith \& Fulham, Westminster, the City of London $\&$ Camden) that drive its anomalous performance. 


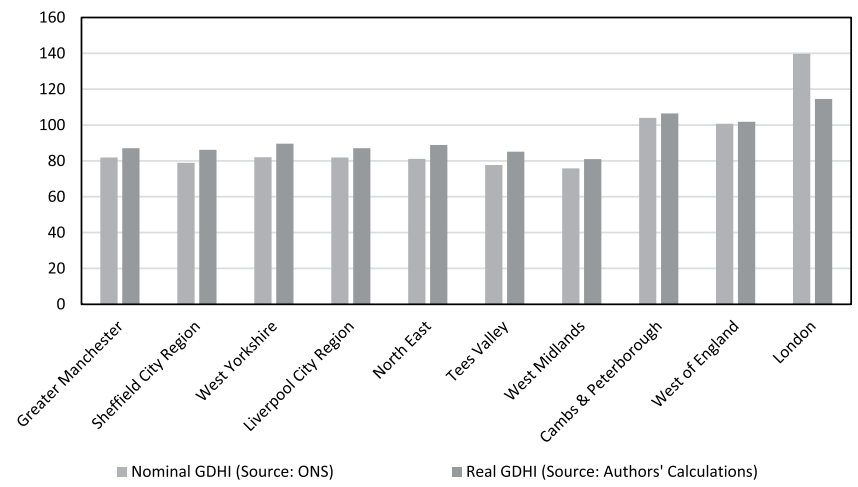

Fig. 4. GDHI Per Capita in Combined Authorities (UK = 100). Sources: (ONS, 2018f) and authors' calculation as specified.

\subsection{INEQUALITY}

As GDHI is based upon mean incomes, it can be skewed by a relatively small number of extremely high earners. Similar issues clearly arise in the case where wealth is concentrated or where there is an unusually wide spread of rents in the property market. It should be noted that this only poses a problem for regional analysis when there are marked differences in structure between regions. In practical terms, this effect is visible but only in London, the South East and East of England.

The single largest contributor to GDHI is wages and salaries, with employers' social contributions also likely to be broadly proportional to these. High quality data in the form of the Annual Survey of Hours and Earnings (ASHE) (ONS, 2017b) exist on both mean and median wages in the UK. Considering the delta between these can give a crude measure of the impact of extremely high earners on average earnings. In all regions outside the Greater South East, median full-time earnings are between $83 \%$ and $87 \%$ of mean full-time earnings. These figures are $80.3 \%, 80.2 \%$ and $76.4 \%$ for the East of England, the South East and London, respectively. 
In fact, if one uses the upper-bound price levels calculated previously and the ASHE dataset, median real full-time wages of Londoners are the second-lowest in the UK (after the South West). By this measure, there is no North-South divide in the $U K$. In fact, regional differences in median full-time earnings almost vanish and there is very little geographical pattern to them. Mean wages are, of course, another matter entirely since they are skewed by the earnings of the very wealthy and it is here that the traditional North-South divide reasserts itself.

This implies that it is the wages of those towards the top of the income distribution that show notable divergence between regions. For those on low or medium incomes (around $75 \%$ of the population), the difference in regional incomes is approximately equal to the difference in prices. Indeed, tentative evidence suggests that 99th percentile wages for employees working in London are 6.9 times median wages, compared to just 4.7 times in the rest of the country (ONS, 2016b). The upshot of this is that there is no systematic wage incentive for workers around the middle of the income distribution to relocate, which accords with what economic theory would predict.

Meanwhile, non-wage income (particularly from property) is considerably higher in the South of England than elsewhere, reflecting the concentration of wealth in that area. Analysis suggests that the spread in rents (which determine the imputed housing services ascribed to owner-occupiers) is much greater in London and the South East than elsewhere. Median rents are over $90 \%$ of mean rents in every region outside the Greater South East (in London the equivalent figure is $85.5 \%$ according to the Valuation Office Agency, 2018). To the extent that income of the bottom $80 \%$ (or even $90 \%$ ) of the population distribution might be considered a better measure of aggregate welfare, it may be worth seeking to develop ways in which to take this into account. 
One additional issue that regional policy makers may face when using GDHI is that it measures income after taxes and benefits have been paid. As a measure of the income that people ultimately have to spend, this is conceptually the correct thing to do. Many regional policy makers, however, may be interested in income before Government intervention. This is also reported by the ONS in the GDHI statistics, albeit under the guise of 'primary income' (in both cases, per capita measurements should be used). When comparing tax and spending policies, the nominal data (as published) should be used, whereas if one is interested in assessing real incomes (excluding taxes and benefits) then an adjustment needs to be made for differing relative consumer price levels.

\subsection{THE INDEX OF MULTIPLE DEPRIVATION}

The prospect of Brexit may afford the opportunity to move away from traditional funding formulae based upon GVA per capita. One alternative measure that has attracted attention from policy makers in the local government sphere is the IMD. This official statistic acknowledges that there are multiple facets of deprivation and has been produced for England (Ministry of Housing Communities \& Local Government, 2015), Scotland (Scottish Government, 2016) and Wales (Welsh Government, 2015). A similar index is also produced by the Northern Ireland Statistics and Research Agency (2017). This official statistic has been used as a measure of deprivation by recent work on well-being (Abreu, Oner, Brouwer, \& van Leeuwen, 2018). The IMD focusses particularly heavily on identifying areas where deprivation is particularly heavily concentrated. Whilst this might be considered a strength, it also poses certain challenges for regional policy makers. 
Firstly, it only focusses on a subset of the total community. This is both a strength and a weakness - there is clearly value in considering the most deprived households. It is important to identify those areas where deprivation is particularly concentrated. Nevertheless, it does not necessarily allow us to identify the extent to which deprivation is due to inter-area inequality (in which case the focus is rightly on spatial disparities) as opposed to intra-area inequality (as is the case in certain parts of London).

Moreover, the presence of deprived communities does not necessarily indicate weakness or absence of opportunity in the regional economy. Tower Hamlets remains one of the most deprived areas of the country, but this is not due to an absence of economic activity in the borough (which boasts a surfeit of highly paid jobs due to the presence of Canary Wharf). Rather, factors such as a lack of skills, social capital and networks lead to the inhabitants being unable to access opportunities that are there. The result is a clearly bifurcated local labour market.

Furthermore, the IMD does not avoid the 'cost of living' issues identified above. In the English IMD, the overall rank of an area is extremely highly correlated with its rank on the income portion (Ministry of Housing Communities \& Local Government, 2015). In fact, a correlation coefficient of 0.95 means that we can almost perfectly predict an area's relative overall deprivation from its deprivation on an income score. The problem here is that the incomes in question are nominalonce again they fail to adjust for differences in prices across the country. Indeed, our evidence suggests that there is a strong rationale for adopting a more holistic view of regional disparities, such as that proposed by Perrons and Dunford (2013) with the clear caveat that any part of the index that is based upon income should adjust for price differences across regions (and particularly in London). 


\subsection{CONCLUSION}

This chapter has shown that relative regional price levels have a considerable impact on regional incomes. This has important consequences given that local authorities with lower nominal per capita household disposable income tended to vote in favour of Brexit. The same pattern is visible for wages. It should also be absolutely critical in any future decision regarding funding flows, which is a theme we will return to in our policy chapter. This will certainly be true in a post-Brexit environment, but we argue that our evidence, combined with known flaws in the GVA per capita measure, should also cause the EU to fundamentally reassess its own structural fund and cohesion fund. The issues that exist in the UK are also visible across Europe, and many of the policy recommendations we make in Chapter 4 are likely to be applicable in a variety of European states. As such, although these recommendations are framed in terms of Brexit, they have a pan-European (and, indeed, international) dimension.

Our evidence suggests that present allocation mechanisms are poor. However, given the present state of the data it is not possible to reliably determine if such funds are making a difference at the macrolevel. In the British context, London's GDHI per capita has risen from $22 \%$ above the UK average in 1997 to $40 \%$ above the UK average in 2016. Is this due to improved economic performance (and can the rest of the country learn from it?) or does it merely reflect a rise in average prices (especially housing)? These questions matter, and they matter more than ever in a post-Brexit context. Improving measurement to the point of being able to offer longerterm solutions is a key area for future research and a major policy recommendation of this book.

Moreover, returning to the theme of Rodríguez-Pose (2018) and others (Goodwin \& Heath, 2016; Kriesi \& Pappas, 2015): is the current wave of populism spanning the 
globe, of which Brexit is just an example, a manifestation of regional policy gone wrong? Is the problem not so much one of individuals being 'left behind' but rather regions becoming 'places that don't matter' (Goodwin \& Heath, 2016; Kriesi \& Pappas, 2015)? Data on household incomes can only partially answer this question: incomes may be related to where individuals live, but they also fundamentally reflect the characteristics of those who choose (or are compelled by either policy or a lack of wherewithal) to live there. The next chapter seeks to address this question more directly: how productive are different regions in the light of subnational price variations? The subsequent chapter then asks the crucial question: in light of both Brexit and this new evidence, what policy options can we take to enhance regional economic performance?

\section{NOTES}

1. https://www.telegraph.co.uk/news/2017/09/07/london-nolonger-uks-expensive-place-buy-pint-beer/

2. As is standard in such analysis (Deaton \& Dupriez, 2013; Ley, 2005; OECD, 2012), we used plutocratic rather than democratic weights here (see Fisher \& Fisher, 2005, for a discussion of the value-judgements implicit in the choice of weights). The resultant price levels are thus well suited to deflating GDHI per capita. The trade-off is that the weights may not mirror the experience of a 'typical' individual as they give more weight to those with higher expenditure (typically high-income individuals).

3. Obviously there are some stark differences - dividends can be altered or suspended at the directors' discretion, whilst coupon payments are unchanging. Rent typically falls somewhere inbetween, with infrequent changes. The running yield on property is often higher than many other assets due to the costs and difficulties associated with purchase or sale of property as well as maintenance costs and the risk of non-occupancy, rent arrears, etc. 
4. Bilateral Laspeyres and Paasche indices are calculated for each region-pair (with the former being a weighted arithmetic mean and the latter a weighted harmonic mean), before computing a bilateral Fisher index (the geometric average of Laspeyres and Paasche indices) and using the modified Eurostat-OECD EKS procedure to obtain a series of transitive relative price levels.

5. This is admittedly a strong assumption, but is not unsupportable: local price variations mostly reflect differences in the quality of amenities. In contrast, price differences over larger areas mostly reflect differences in the cost of living. The litmus test is whether the labour market is largely self-contained: can one live in place $\mathrm{A}$ and work in place B? Groceries in town A may be more costly than in town $B$ due to the fact that town $A$ has a preponderance of Waitrose stores whilst town B is served by Lidl. As the two are proximate, those living in town A can shop at Lidl in town B (and vice versa). Although measured prices appear different, they are in fact identical. In contrast, a pint of (the same) beer is significantly more costly in London than in Yorkshire, even if the pub is otherwise identical due to differences in the cost of providing the service (staff costs, rents, etc.). It is not feasible to travel from London to Yorkshire simply to enjoy a cheaper pint! Measured price differences do indeed reflect real price differences in this case. The same logic applies for housing costs, etc. 